\title{
Über die Xanthoproteinreaktion.
}

Von

K. Inouye.

(Aus dem physiologischen Institut der Universität Heidelberg.)

(Der Redaktion zugegangen am 24. August 1918.)

Das Auftreten der Farbenreaktionen von Eiweißstoffen beruht bekanntlich in den meisten Fällen auf der Bildung gefärbter Verbindungen von bestimmten Bausteinen mit den hinzugesetzten Reagenzien. Man kann deshalb durch das Ergebnis einer Farbenreaktion auf die An- oder Abwesenheit eines der Bausteine sowie einer reaktionsfähigen Atomgruppe hinweisen. Die Untersuchungen über die dabei stattfindenden Vorgänge und die gebildeten Farbstoffe sind demgemäß von Bedeutung für die Beurteilung der Konstitution des Eiweißmoleküls.

Unter den Farbenreaktionen ist die Xanthoproteinprobe schon lange allgemein bekannt, trotzdem ihre Natur noch unaufgeklärt bleibt. In der Tat handelt es sich bei dieser Reaktion um einen komplizierten Prozeß, welcher aus verschiedenen Einzelreaktionen zusammengesetzt ist.

Bei der Einwirkung von Salpetersäure auf Eiweißkörper findet unter anderem eine Nitrierung unter Bildung von gefärbten und nicht gefärbten Derivaten statt. Betrachtet man diesen Vorgang von den Gesichtspunkten der Farbstoffbildung aus, so kommt das kürzlich von A. Kossel und E. L. Kennaway beschriebene Nitroarginin ${ }^{1}$ ) nicht in Betracht, da dieses farblos ist, ebensowenig diejenigen Körper, die erst durch energische Einwirkung der Säure entstehen, wie die p-Nitrobenzoesäure

1) Diese Zeitschrift, Bd. 72 (1911), S. 486. 
von M. Nencki und N. Sieber, ${ }^{1}$ ) da sich gewöhnlich bei der genannten Probe keine so eingreifende Säurewirkung abspielt.

Maßgebend für die Xanthoproteinreaktion sind offenbar die aromatischen Eiweißbausteine, die selber durch Nitrierung in gefärbte Derivate übergeführt und durch weitergehende Spaltung verändert werden können. So z. B. glaubt Welter ${ }^{z}$ ) Pikrinsäure aus der mit Salpetersäure behandelten Seide erhalten zu haben. Freilich ist nach den unten angeführten Untersuchungen kaum anzunehmen, daß diese Säure eine direkte Ursache der Xanthoproteinreaktion ist.

Daß sich auch Tryptophan an dieser Reaktion beteiligen kann, geht aus den Arbeiten von E. Salkowski, ${ }^{\text {) }}$. E. Rohde ${ }^{4}$ ) und E. Abderhalden und M. Kempe ${ }^{5}$ ) hervor.

Welcher aromatische Baustein bei der Xanthoproteinreaktion wirklich der Nitrierung unterliegt, ist eine noch offene Frage. 0. v. Fürth ${ }^{6}$ ) hat das «Xanthoprotein aus Casein der Säurehydrolyse und der fermentativen Spaltung unterworfen und dabei verschiedene nitrierte Albumosen erhalten; ferner hat er durch ziemlich starke Einwirkung von Salpetersäure einen nitrierten Farbstoff «Xanthomelanin » hergestellt und untersucht. Das Xanthomelanin stellt aber einen Körper von komplizierter Zusammensetzung dar und gibt uns keine entscheidende Antwort auf unsere Frage.

Die direkte Abspaltung gut definierter Nitrokörper aus dem sogenannten Xanthoprotein kann allein diese Frage endgültig lösen. $\mathrm{Zu}$ diesem $\mathrm{Zwecke}$ wurde die vorliegende Arbeit auf Veranlassung von Herrn Professor A. Kossel unternommen, dem ich an dieser Stelle für seine freundliche Unterstützung meinen aufrichtigsten Dank aussprechen möchte.

Zum Zweck der folgenden Untersuchungen habe ich Seiden-

1) Ber. d. Deutsch. chem. Ges., Bd. 18 (1885), S. 394.

2) Ann. de chim., Bd. 29 (1796), S. 301; Scherers Journal, Bd. 3 (1799), S. 715.

3) Diese Zeitschrift, Bd. 12 (1888), S. 218.

4) Diese Zeitschrift, Bd. 44 (1905), S. 170.

5) Diese Zeitschrift, Bd. 52 (1907), S. 212.

6) Habilitationsschrift, Straßburg 1899 .

Hoppe-Seyler's Zeitschrift f. physiol. Chemie. LXXXI. 
fibroin nitriert und das Nitroprodukt durch Schwefelsäure gespalten. Aus dem Reaktionsgemisch konnte ich neben farblosen Spaltungsprodukten ein Mononitrotyrosin isolieren. Um zu entscheiden, ob auch Phenylalanin nitriert wird, ist noch ein weiterer Versuch notwendig. Demzufolge ist man berechtigt, zu sagen, daß die Xanthoproteinreaktion zum Teil durch die Bildung des Nitrotyrosins bedingt ist.

\section{Experimentelles.}

Um den stärksten Erfolg der Nitrierung mit der geringsten Nebenwirkung zu erzielen, erwies sich folgendes Verfahren als das zweckmäßigste :

$30-50 \mathrm{~g}$ Seidenabfälle wurden in einer Stutze mit verdünnter Salpetersäure $\left.(20 \%)^{1}\right)$ überschüttet, gut durchgerührt und 48 Stunden bei Zimmertemperatur stehen gelassen. Die intensiv gelb gefärbte "Nitroseide» wurde nun von der blaßgelb gewordenen Salpetersäure getrennt, gründlich mit Wasser, dann mit Alkohol und Äther gewaschen und in der Luft getrocknet. Die Ausbeute an der so erhaltenen Nitroseide, die schön goldgelb gefärbt war und ihre Fadenform bewahrt hatte, war $85-90 \%$ des verwandten Materials.

Nach verschiedenen Versuchen, nitrierte Spaltungsprodukte $\mathrm{zu}$ isolieren, führte das folgende Verfahren zum Ziele. $35 \mathrm{~g}$ Nitroseide wurden mit einer Mischung von $105 \mathrm{~g}$ konzentrierter Schwefelsäure und $180 \mathrm{~g}$ Wasser 10 Stunden am Rückflußkühler gekocht. Das heiße stark gefärbte Reaktionsgemisch wurde zuerst mit einer heißen konzentrierten, sodann mit verdünnter Ätzbarytlösung bis zur fast neutralen Reaktion versetzt, der entstandene Niederschlag abgenutscht und mehrmals ausgekocht. Das rotgelbe Filtrat und das Waschwasser wurden vereinigt, auf etwa $150 \mathrm{ccm}$ eingedampft, mit Schwefelsäure bis

1) Zusatz von Harnstoff wirkt nicht günstig. In einer Probe mit Harnstoff bekam ich ein bedeutend schwächer gefärbtes Präparat, außerdem trat dabei die hydrolysierende Wirkung stark hervor. Zusatz von Harnstoff vermindert die Zahl der eintretenden Nitrogruppen, wie v. Fürth angegeben hat. 1. c. S. 22. 
zu einem Gehalt von 5\% versetzt und durch vorsichtigen Zusatz von Phosphorwolframsäure ausgefällt. Der Phosphorwolframsäureniederschlag wurde abgesaugt, mit 5\% iger Schwefelsäure ausgewaschen, im Wasser fein zerteilt und mit Barytwasser zerlegt. Das bräunlichrote Filtrat vom Barytniederschlag wurde durch Kohlensäure vom Überschuß des Baryts befreit und zur Trockne eingedampft; der schön rot gefärbte Rückstand in einer nicht zu kleinen Menge ausgekochten Wassers aufgenommen und durch vorsichtigen Zusatz von Schwefelsäure von Baryt befreit, wobei die Farbe der Lösung ins Gelbe umschlug. Nach dem Eindampfen bis zum Beginn der Krystallisation blieb die Lösung über Nacht stehen. Nun wurden die ausgeschiedenen gelben, nadelförmigen Krystalle, deren Menge $0,55 \mathrm{~g}$ betrug, abgesaugt und wiederholt aus heißem Wasser, nötigenfalls unter Zusatz von Tierkohle, ${ }^{1}$ ) umkrystallisiert. Sie zeigten dann einen konstanten Schmelzpunkt von $215-216^{\circ}$, welcher mit dem des Nitrotyrosins aus Tyrosin übereinstimmte. Die Krystalle gaben Rotfärbung beim Erwärmen mit Millons Reagens und tiefrote Färbung mit Diazobenzolsulfosäure bei Gegenwart überschüssigen Natriumcarbonats.

Die Analyse der Krystalle ergab folgendes:

$0,1276 \mathrm{~g}$ Substanz gaben $13,6 \mathrm{~cm} \mathrm{~N}$ bei $18^{\circ} \mathrm{C}$. und $755,5 \mathrm{~mm}$ Bar., d. i. $12,13 \%$.

Berechnet für $\mathrm{C}_{9} \mathrm{H}_{10} \mathrm{NO}_{3} \cdot \mathrm{NO}_{2}=12,39 \%$.

Diese Formel stimmt mit der eines Mononitrotyrosins überein.

Nitrotyrosin wurde zuerst von A. Strecker ${ }^{2}$ ) durch die Einwirkung von Salpetersäure auf Tyrosin gewonnen. In reinem Zustande ist es in Wasser schwer löslich, in unreinem leichter löslich. Die wässerige Lösung ist hellgelb und reagiert schwach sauer. In Mineralsäuren löst es sich leicht mit gelber Farbe, durch überschüssige Alkalien wird die Lösung rot. In Methyl-,

1) Tierkohle und andere fein zerteilte Niederschläge adsorbieren den Farbstoff sehr stark. Infolge dessen läuft das Waschwasser noch immer etwas gefärbt ab, selbst nachdem man den Niederschlag oftmals ausgekocht hat.

2) Liebigs Ann., Bd. 73 (1850), S. 70. 
Äthyl-, Amylalkohol und Äther ist es unlöslich, ebenso in Eisessig. In der wässerigen Lösung rufen Silbernitrat + Baryt und Phosphorwolframsäure + Schwefelsäure gefärbte flockige Niederschläge hervor, die sich wieder im Überschuß der Fällungsmittel lösen. Quecksilberchlorid und -acetat erzeugen keinen Niederschlag.

Durch seine charakteristische Färbung - gelb bei saurer, rot bei alkalischer Reaktion - wies das Filtrat der Phosphorwolframsäurefällung noch auf weitere Nitrokörper hin. Es wurde zur Abscheidung der Phosphorwolframsäure und Schwefelsäure mit Barytwasser versetzt und der Überschuß des Baryts durch Kohlensäure entfernt. Beim Eindampfen schieden sich $0,3 \mathrm{~g}$ Substanz ab, welche nach mehrmaliger Umkrystallisation aus gelben Blättchen vom Schmelzpunkt von 233-2340 bestanden.

Dieser Körper zeigte einen Stickstoffgehalt von 12,26\% (berechnet für Mononitrotyrosin: 12,39\%), wich hingegen bezüglich des Schmelzpunktes von dem oben erwähnten Präparat ab und war auch bedeutend leichter löslich. Es ist hiernach wahrscheinlich, daß es sich um unreines Mononitrotyrosin handelte.

Die Mutterlauge der obigen Krystalle wurde weiter eingedampft. Beim Erkalten erstarrte die ganze Masse zu einem süß schmeckenden Krystallbrei, aus dem sich bei der fraktionierten Krystallisation zwei verschiedene farblose Körper trennten. Der schwerer lösliche Körper $(10 \mathrm{~g})$ krystallisierte aus wässeriger Lösung in Form von Nadeln, der andere $(5 \mathrm{~g})$ in Prismen.

Da nach Welter ${ }^{1}$ ) auch Pikrinsäure zu erwarten war, so schüttelte ich bei einem anderen Versuche die bei der Hydrolyse resultierende Flüssigkeit gleich nach der Zersetzung mit Äther aus. Von der gelb gefärbten ätherischen Lösung wurde der Äther abdestilliert, der Rückstand in Wasser gelöst. In der gelben Lösung ließ sich jedoch keine Pikrinsäure nachweisen.

1) 1. c. 
Ferner versetzte ich $15 \mathrm{~g}$ Seidenabfälle mit 6 Gewichtsteilen konzentrierter Salpetersäure und stellte das Gemisch zwei Tage lang in den Keller. Die hellgelbe Auflösung wurde mit Äther erschöpft und die ätherische Lösung weiter auf Pikrinsäure geprüft, aber mit negativem Resultat.

Somit ergibt sich, daß sich die Bildung von Pikrinsäure bei niedriger Temperatur nicht nachweisen läßt. Folglich kann von einer Beteiligung der Pikrinsäure an der Xanthoproteinreaktion nicht die Rede sein. Selbstverständlich ist es nicht ausgeschossen, daß bei einem eingreifenden Verfahren, wie es von Welter angewandt worden ist, Pikrinsäure entsteht. 